\title{
Cationic Antimicrobial Peptide Cytotoxicity
}

\author{
Garry Laverty* and Brendan Gilmore
}

Lecturer in Pharmaceutical Science, School of Pharmacy, Medical Biology Centre, Queen's University of Belfast, Belfast, Ireland

\author{
Received: January 14, 2014; Accepted: February 25, 2014; Published: February 27, 2014 \\ *Corresponding author: Garry Laverty, Lecturer in Pharmaceutical Science, School of Pharmacy, Medical Biology Centre, Queen's University of Belfast, \\ Belfast, BT9 7BL, Ireland, Tel: +44-(0)-28-9097-2273; E-mail: garry.laverty@qub.ac.uk
}

\begin{abstract}
Fluorescence microscopy serves as a valuable tool for assessing the structural integrity and viability of eukaryotic cells. Through the use of calcein AM and the DNA stain 4,6-diamidino-2-phenylindole (DAPI), cell viability and membrane integrity can be qualified. Our group has previously shown the ultra-short cationic antimicrobial peptide $\mathrm{H}-\mathrm{OOWW}-\mathrm{NH}_{2}$; the amphibian derived 27-mer peptide Maximin4and the ultra-short lipopeptide $\mathrm{C}_{12}-\mathrm{OOWW}-\mathrm{NH}_{2}$ to be effective against a range of bacterial biofilms [1], displaying potential for use in the prevention of medical device-related infections [2]. Analysis of fluorescence micrographs, after staining with calcein AM and DAPI, shows the likely mode of cytotoxic action of cationic antimicrobial peptides and lipopeptides are via direct membrane disruption in eukaryotic cells. Selectivity is towards cidal action against prokaryotic cells, whose membranes are anionic in composition, such as those of bacteria, rather than for neutral zwitterionic membranes of eukaryotic cells. Membrane selectivity is determined by a multitude of physical parameters, particularly charge and hydrophobicity. The charge of the antimicrobial determines the extent of the initial electrostatic interactions with both prokaryotic and eukaryotic membranes, with a larger cationic charge favoring antimicrobial action. Tailoring of these properties is likely to be the key in successfully transferring antimicrobial peptides from laboratory experiments into clinical practice as safe pharmaceutical formulations.
\end{abstract}

Keywords: Lipopeptides; Cytotoxic; Fluorescence microscopy; Tissue culture; Qualitative

\section{Introduction}

\section{The cytotoxic: therapeutic balance in antimicrobials}

Cytotoxicity relates to the ability of a compound to exert a toxic effect on cells, or more specifically on human cells. No drug is completely free from toxicity, with associated adverse drug reactions generally the most common reason for withdrawal of approved drugs $[3,4]$. There instead exists a balance between the need for treatment and the level of toxicity produced at therapeutic levels. As a class of drugs, antimicrobials are particularly troublesome with regard to cytotoxicity, as their significant role is to ultimately achieve microbial cell death [5]. For example, some antimicrobial peptides may provide benefit at lower antimicrobially active concentrations with regard to prevention of infected wounds; however, at higher concentrations they may exhibit cytotoxicity that might adversely affect wound healing [6]. Antiseptic agents whose main mechanism of action is the targeting of membranes pose problems for therapeutic use in that they will exert a detergent-like effect, compromising both microbial and mammalian cell membranes due to antimicrobial and cytotoxic effects [7]. In the host, these effects can range from irritation at the site of exposure to severe vascular injuries and life-threatening events such as seizures or cardiac arrhythmias [5] when antiseptics are used clinically as a skin disinfectant, as a lavage for infected wounds, and within antimicrobial catheters [8]. Cationic antimicrobial peptides have been shown to exert their antimicrobial effect by selective permeabilization of predominantly negatively charged bacterial membranes [9]. However, just like antimicrobial action, cytotoxicity may be produced by a multitude of mechanisms. The treatment of cells at toxic concentrations can result in loss of membrane integrity and cell lysis, with resulting leakage of cytoplasmic cell contents, in a process termed necrosis. Alternatively the compound may invoke genetically programmed cell death, called apoptosis, where cells stop actively dividing and therefore growing [10]. Apoptotic markers are well defined and include changes in the refractive index of the cell, destruction of the nucleus with cleavage of DNA into fragments and shrinkage of the cytoplasm [11]. These markers are not present in necrosis as membrane destruction is rapid, with limited time for activation of apoptotic mediators. Cells undergoing apoptosis will eventually undergo secondary necrosis as metabolic pathways shut down, with loss of membrane integrity resulting in cell lysis [12]. The differentiation of microbial and human cells is important for antimicrobials, in order to achieve resolution of infection while also limiting antimicrobial-related damage. However, in the development of new antimicrobials, there is a reduced likelihood that animal and human toxicity will halt the developmental process. This is shown by a survey of seven British pharmaceutical companies between 1964 and 1985 in which only eleven (10\%) of new antimicrobials tested were halted due to a problem with toxicity profiles compared with seventeen (16\%) of other drug groups [13-15]. Poor antimicrobial and pharmacokinetic efficacy were deemed more problematic. Despite the reduced likelihood of an antimicrobial being halted at the developmental stage due to toxicity factors, withdrawals have occurred after clinical approval, with resulting patient morbidity, death and loss of revenue. For example, temafloxacin was approved for use as an antibiotic in 1992 but six months after its approval it was withdrawn from the market because of toxicity associated with haemolytic anaemia, 
clotting disorders and liver and kidney impairment [16]. Therefore cytotoxic profiling is a necessity for the future design of antimicrobials. Ultrashort antimicrobial peptides, lipopeptides and the amphibian peptide Maximin-4 have previously been shown by our group to display antimicrobial activity in the $\mu \mathrm{g} /$ $\mathrm{mL}$ range against a range of important nosocomial pathogens [1]. To evaluate their potential use as anti-biofilm agents for medical device applications, it is necessary to formulate toxicity profiles to assess their relative action against the cells of eukaryotic/ mammalian/human hosts. The standard antimicrobials rifampicin and vancomycin are used as comparators.

\section{Methods}

\section{Chemicals and reagents}

Phosphate buffer saline (PBS) tablets, 3-(4,5-dimethylthiazol2-yl)-2,5-diphenyltetrazolium bromide (MTT), DAPI, calcein AM, vancomycin (as hydrochloride hydrate) and rifampicin were obtained from Sigma-Aldrich (Dorset, UK). Methanol, ethanol and dimethyl sulphoxide (DMSO) analytical reagent grade were obtained from Fisher Scientific (Leicestershire, UK). Dulbecco's modified Eagle's medium (DMEM) containing $4500 \mathrm{mg} / \mathrm{L} D$-glucose, $L$-glutamine, trypsin with ethylenediaminetetra-acetic acid (EDTA) and 1\% penicillin/ streptomycin obtained from Invitrogen (Paisley, UK). 5\% v/v foetal bovine serum was obtained from Biosera (East Sussex, UK). Rink amide 4-(2',4'-dimethoxyphenyl-Fmoc-aminomethyl)phenoxyacetamido-MHBA (MBHA) resin, all 9-fluorenylmethoxy carbonyl (Fmoc) L-amino acids and 2-(1H-benzotriazole-1yl)-1,1,3,3-tetramethyluronium hexafluorophosphate (HBTU) were obtained from Merck Chemicals Ltd. (Nottingham, UK). Dodecanoic (lauric) acid was obtained from Sigma-Aldrich (Dorset, UK). All other reagents/solvents were peptide synthesis grade.

\section{Peptide synthesis}

Peptides were synthesized using standard 9-fluorenylmethoxy carbonyl (Fmoc) solid phase protocols on Rink Amide MHBA resin, using a CEM Liberty (Buckingham, UK) microwave enhanced automated peptide synthesizer. Peptide elongation was effected using standard HBTU coupling chemistry in dimethylformamide (DMF) solvent with four-fold molar excess of diisopropylethylamine (DIEA) in $N$-methyl-2-pyrrolidone (NMP) and a three-fold molar excess of each Fmoc-protected amino acid or free fatty acid. Fatty acids were coupled using standard (microwave enhanced) amino acid coupling conditions $\left(18 \mathrm{~W}, 75^{\circ} \mathrm{C}, 300 \mathrm{~s}\right)$ employed for all syntheses. All peptides were cleaved from the resin using 95\% trifluoroacetic acid, $2.5 \%$ triisopropylsilane and $2.5 \%$ thioanisole $(2 \mathrm{~h}$, room temperature), following standard work-up (crude product was dissolved in ethyl acetate and subjected to a series of washes with $1 \mathrm{mM} \mathrm{HCl} \mathrm{(3}$ $\mathrm{x} 50 \mathrm{ml})$ and water $(3 \times 50 \mathrm{ml})$ and dried over anhydrous $\mathrm{MgSO}_{4}$. The identity of each lipopeptide was confirmed by electrospray mass spectroscopy (Thermo Finnigan LCQ Deca ion trap). Peptide purity was analyzed by RP-HPLC using a Gemini C18, 250 mm x $4.6 \mathrm{~mm}$ column (Phenomonex, UK), a 2-60\% acetonitrile gradient [ $30 \mathrm{~min}$ ] in $0.05 \% \mathrm{TFA}-$ water at a flow rate of $1 \mathrm{~mL} / \mathrm{min}$.
All peptides/lipopeptides were found to have $>90 \%$ purity.

\section{Qualitative cell survival analysis: fluorescence microscopy}

HaCaT keratinocyte cell line (Cell Line Services, Eppelheim, Germany, collection number: 400693) were cultured in DMEM containing $4500 \mathrm{mg} / \mathrm{L} D$-glucose from Invitrogen (Paisley, UK), supplemented with $2 \mathrm{mM} L$-glutamine foetal bovine serum and $1 \%$ penicillin/streptomycin. Cells were grown at $37^{\circ} \mathrm{C}$ and $5 \% \mathrm{CO}_{2}$ and subcultured at $80-90 \%$ confluency. Subculturing consisted of removal of spent medium, rinsing of the adherent cell surface with PBS before treatment with trypsin-EDTA for cell monolayer detachment. Cell viability and morphology were assessed by fluorescence microscopy. HaCaT cells were cultured (until at least a third passage) and inoculated into sterile polystyrene Nunc $^{\text {TM }}$ 96-well tissue culture treated microtitre plates (VWR International Ltd, Leicestershire, UK) at a concentration of $1 \mathrm{x}$ $10^{4}$ cells/well and incubated at $37^{\circ} \mathrm{C}$ and $5 \% \mathrm{CO}_{2}$ for $24 \pm 1$ hour, until approximately $90 \%$ confluency as described above. After this time, the medium was removed and replaced with fresh growth medium, as described above, but containing a range of concentrations (1000 to $3.91 \mu \mathrm{g} / \mathrm{ml}$ ) of individually prepared vancomycin, rifampicin, Maximin-4, $\mathrm{H}-\mathrm{OOWW}-\mathrm{NH}_{2}$ and $\mathrm{C}_{12}-$ OOWW- $\mathrm{NH}_{2}$ for 1 hour. $90 \%$ ethanol only controls were also tested as a positive control for total kill, as evidenced by of the method of Mossman (Mosmann, 1983) and a negative control, containing only medium, was also tested. After 1 hour of exposure at $37^{\circ} \mathrm{C}$ and $5 \% \mathrm{CO}_{2}$, medium was removed and cells washed with PBS in order to remove residual compounds under study. Cells were exposed concurrently to $100 \mu \mathrm{l} \mathrm{PBS}$ at $37^{\circ} \mathrm{C}$ containing 300 nM DAPI and $5 \mu \mathrm{M}$ calcein AM. Cells were incubated at $37^{\circ} \mathrm{C}$ and $5 \% \mathrm{CO}_{2}$ for 30 minutes before being washed five times with PBS. Cells were then analysed by fluorescent microscopy using filters corresponding to the manufacturers recommended excitation wavelength of both DAPI $(350 \mathrm{~nm})$ and calcein AM $(494 \mathrm{~nm})$. Cell images were also taken at $555 \mathrm{~nm}$ to aid in the assessment of cell/ cell membrane integrity. Six replicates were produced for each concentration of antimicrobial to ensure accurate qualitative data was obtained.

\section{Results and Discussion}

Through the use of a variety of assays, the mode of cellular destruction by a given cytotoxic compound can be determined. The use of cell based assays has increased steadily over recent years and there is now a trend for pharmaceutical companies to revert to high throughput chemical cytotoxicity assays that utilise cells in correlation with, or in preference to, animal testing [17]. Specific data obtained for each method show high degrees of correlation [18]. In the literature there is an increasing emphasis on the utilisation of haemolysis and MTT assays for antimicrobial peptides [1]. The use of fluorescence microscopy can serve as a useful qualitative tool alongside these methods.

In order to qualitatively evaluate the potential of the synthesised ultrashort cationic antimicrobial peptide $\mathrm{H}-\mathrm{OOWW}$ $\mathrm{NH}_{2}$, Maximin-4 and the ultrashort lipopeptide $\mathrm{C}_{12}-\mathrm{OOWW}-\mathrm{NH}_{2}$ to cause cellular toxicity, fluorescence microscopy was utilized. 
As with the majority of antimicrobials, interaction with the cell membrane of microorganisms is fundamental to the mode of action of cationic antimicrobial peptides. The significant difference in the compositions of eukaryotic membranes in comparison to prokaryotic membranes highlights the important selectivity of these compounds for microbial cells. Cationic antimicrobial peptides will therefore bind preferentially to the negatively charged phospholipid bilayer of bacterial cells [9]. This is advantageous with regard to reducing toxicity in any potential therapeutic environment.

The membrane lytic properties induced by the cationic antimicrobial peptides are confirmed through the use of fluorescence micrographs after staining of exposed HaCaT cell lines with DAPI and calcein AM. The most antimicrobially potent peptides studied in our previous work $[1,2]$ were selected (Maximin-4 and $\mathrm{C}_{12}-\mathrm{OOWW}-\mathrm{NH}_{2}$ ) with vancomycin, rifampicin and $\mathrm{H}-\mathrm{OOWW}-\mathrm{NH}_{2}$ acting as comparative controls and $90 \%$ ethanol as a positive control. Interpretation of these results was based upon the binding of DAPI to DNA-double strands of HaCaT cell lines, yielding a fluorescent blue complex at wavelength 350 $\mathrm{nm}$ [19]. DAPI has been shown to be useful for the detection of nonviable cells with compromised membranes in live cell cultures [20]. It is only when the membrane integrity is compromised that DAPI can enter the cell cytoplasm and pass into the nucleus to stain DNA [21]. Cell viability is determined through the use of calcein AM. Calcein AM is a non-fluorescent lipid-soluble complex that can passively cross intact cell membranes in an electrically neutral form to be converted to the intensely fluorescent calcein [22]. This conversion occurs within the cell cytoplasm by live cells that possess active intracellular esterases (Figure 1). Calcein's hydrophilic and polyanionic character allows it to be retained within living cells. An intense fluorescent green calcein complex visible at $494 \mathrm{~nm}$ was indicative of the presence of viable cells, with the absence of a blue fluorescent DAPI stain at $350 \mathrm{~nm}$ also showing an intact cell membrane as demonstrated by the negative control present in Table 1 [23].

A range of fluorescent micrographs are shown from Table 1 to 6 at both cytotoxic and non-cytotoxic concentrations of antimicrobials. $\mathrm{H}-\mathrm{OOWW}-\mathrm{NH}_{2}$ has a reduced cytotoxic profile shown by the presence of green fluorescent calcein even at concentrations as high as $1000 \mu \mathrm{g} / \mathrm{ml}$. The blue fluorescent DAPI stain is present at similar concentrations, proving membrane disruption does occur but to a lesser extent than the positive $90 \%$ ethanol control or $1000 \mu \mathrm{g} / \mathrm{ml}$ of $\mathrm{C}_{12}-00 \mathrm{WW}-\mathrm{NH}_{2}$. The peptides were only exposed to the HaCaT cell lines for 1 hour as membrane permeabilization was predicted to be a rapid process. As previously shown by our group, significant cell death occurs with peptides such as $\mathrm{C}_{12}-\mathrm{OOWW}-\mathrm{NH}_{2}$ after 24 hour exposure at cytotoxic concentrations $(>62.5 \mu \mathrm{g} / \mathrm{ml})$ [1]. This study shows that cell death occurs within 1 hour exposure at the highest

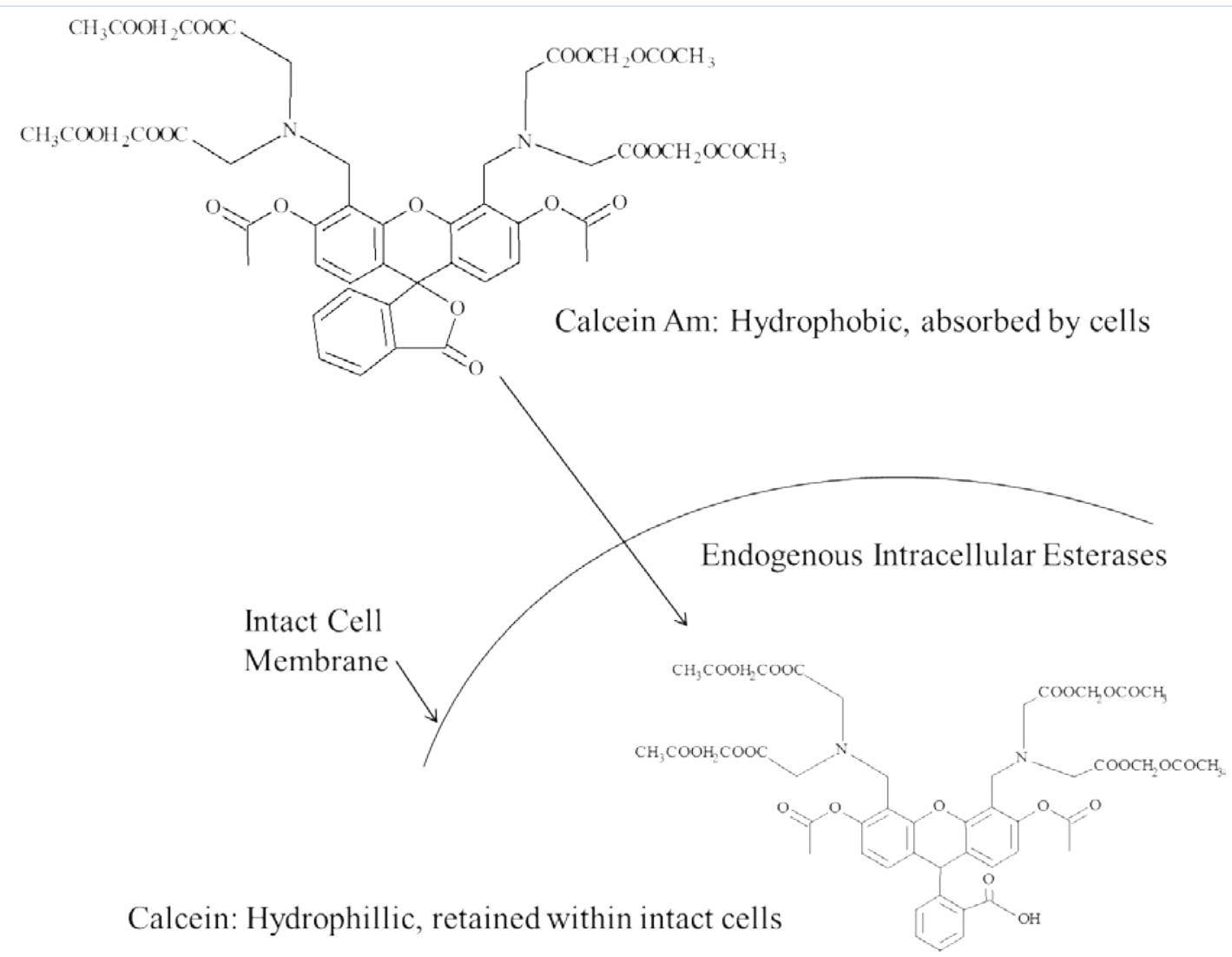

Figure 1: The conversion of hydrophobic calcein AM to the hydrophilic and fluorescent complex calcein by endogenous intracellular enzymes present in viable HaCaT cells. 
Table 1: Fluorescence micrographs showing DAPI and calcein AM counterstains of HaCaT cells after 1 hour exposure to $90 \%$ ethanol (positive control) and medium (negative control).

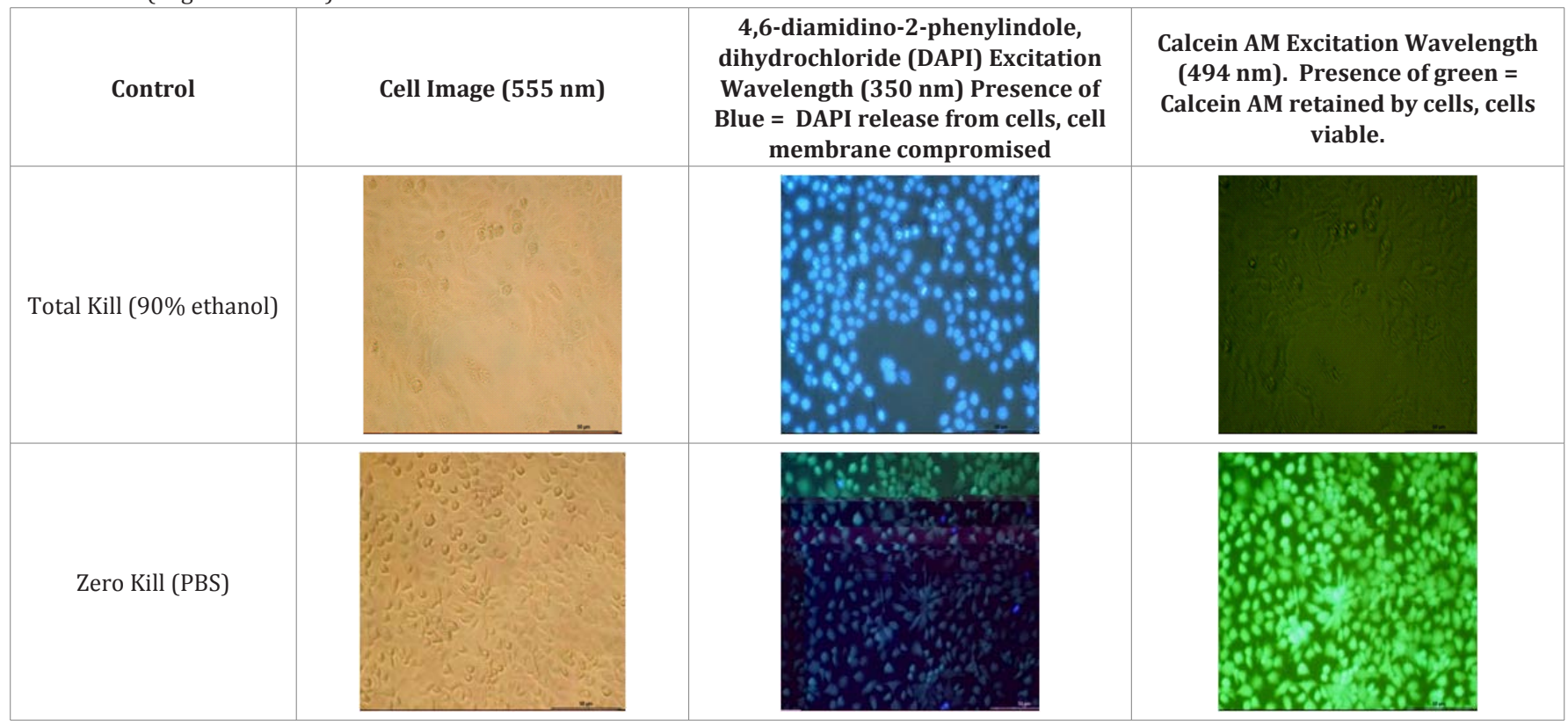

Table 2: Fluorescence micrographs showing DAPI and calcein AM counterstains of HaCaT cells after 1 hour exposure to H-OOWW-NH${ }_{2}$.

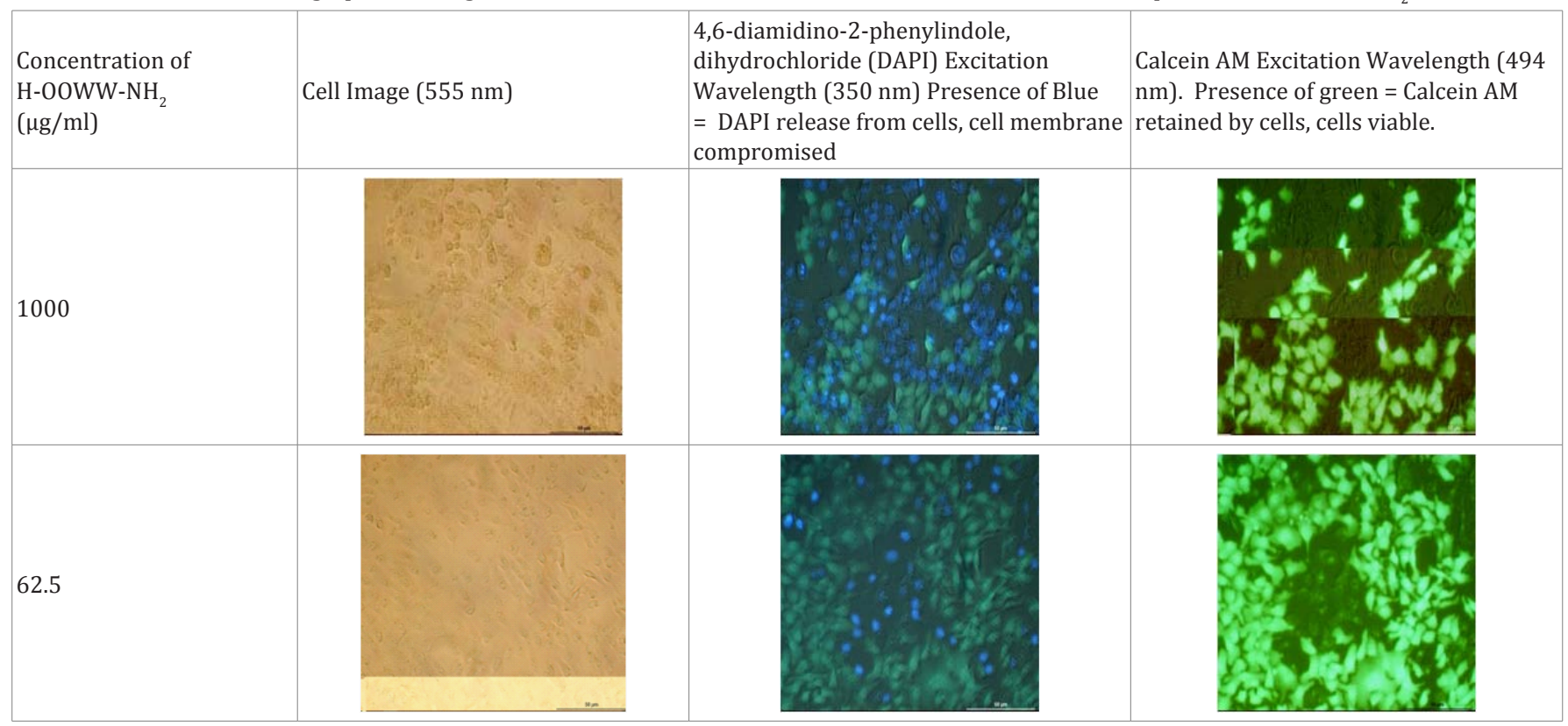

concentration tested $(1000 \mu \mathrm{g} / \mathrm{ml})$. Cell death via is confirmed by fluorescent micrographs. At cytotoxic concentrations of 1000 $\mu \mathrm{g} / \mathrm{ml}$, the peptides Maximin-4 (Table 4) and $\mathrm{C}_{12}-\mathrm{OOWW}-\mathrm{NH}_{2}$ (Table 3) produce normal large and intact nuclear structures (shown by DAPI counterstain) due to membrane lysis, rather than bright clustered bodies which are a typical feature of chromatin condensation and cellular apoptosis relative to controls (Table 1) [24]. For $\mathrm{C}_{12}-\mathrm{OOWW}-\mathrm{NH}_{2}$ (Table 3) and Maximin-4 (Table 4) cytotoxicity and cellular necrosis of HaCaT cells after 1 hour is minimal at $15 \mu \mathrm{g} / \mathrm{ml}$. This concentration corresponds to approximately the Minimum Biofilm Eradication
Concentration (MBEC) for $\mathrm{C}_{12}-\mathrm{OOWW}-\mathrm{NH}_{2}$ and Maximin-4 (both $15.63 \mu \mathrm{g} / \mathrm{ml}$ ) against Staphylococcus epidermidis (ATCC 35984) and Staphylococcus aureus (ATCC 29213) respectively [1,2]. Although these MBEC values are obtained after 24 hour exposure to these peptides, whereas fluorescence results are observed after 1 hour, biofilm eradication kinetics for each peptide after 1 hour show a preference for action against Gram-positive bacterial biofilm rather than HaCaT cells. Minimal cytotoxicity was shown for vancomycin at the highest concentration tested $(1000 \mu \mathrm{g} / \mathrm{ml})$ (Figure 6). Rifampicin expressed low qualitative cytotoxicity at $15 \mu \mathrm{g} / \mathrm{ml}$ but at $1000 \mu \mathrm{g} / \mathrm{ml}$ the presence of DAPI 
Table 3: Fluorescence micrographs showing DAPI and calcein AM counterstains of HaCaT cells1 hour exposure to $\mathrm{C}_{12}-00 \mathrm{WW}-\mathrm{NH}_{2}$.

\begin{tabular}{|c|c|c|c|}
\hline $\begin{array}{l}\text { Concentration of } \mathrm{C}_{12}{ }^{-} \\
\text {OOWW- } \mathrm{NH}_{2} \\
(\mu \mathrm{g} / \mathrm{ml})\end{array}$ & Cell Image $(555 \mathrm{~nm})$ & $\begin{array}{l}\text { 4,6-diamidino-2-phenylindole, dihydrochloride } \\
\text { (DAPI) Excitation Wavelength }(350 \mathrm{~nm}) \\
\text { Presence of Blue = DAPI release from cells, cell } \\
\text { membrane compromised }\end{array}$ & $\begin{array}{l}\text { Calcein AM Excitation Wavelength }(494 \mathrm{~nm}) \text {. } \\
\text { Presence of green = Calcein AM retained by } \\
\text { cells, cells viable. }\end{array}$ \\
\hline 1000 & & & \\
\hline 62.5 & & & \\
\hline 15 & & & \\
\hline
\end{tabular}

Table 4: Fluorescence micrographs showing DAPI and calcein AM counterstains of HaCaT cells after 1 hour exposure to the amphibian-derived peptide Maximin-4.

\begin{tabular}{|l|l|l|l|}
\hline $\begin{array}{l}\text { Concentration of } \\
\text { Maximin-4 } \\
(\mu \mathrm{g} / \mathrm{ml})\end{array}$ & $\begin{array}{l}\text { 4,6-diamidino-2-phenylindole, dihydrochloride } \\
\text { (DAPI) Excitation Wavelength }(350 \mathrm{~nm}) \\
\text { Presence of Blue }=\text { DAPI release from cells, cell } \\
\text { membrane compromised }\end{array}$ & $\begin{array}{l}\text { Calcein AM Excitation Wavelength (494 nm). } \\
\text { Presence of green = Calcein AM retained by } \\
\text { cells, cells viable. }\end{array}$ \\
\hline 1000 & & \\
\hline 62.5 & &
\end{tabular}

Citation: Laverty G, Gilmore B (2014) Cationic Antimicrobial Peptide Cytotoxicity. SOJ Microbiol Infect Dis 2(1): 1-8. DOI: http:// 
Table 5: Fluorescence micrographs showing DAPI and calcein AM counterstains of HaCaT cells after 1 hour exposure to vancomycin.

\begin{tabular}{|l|l|l|l|}
\hline $\begin{array}{l}\text { Concentration of } \\
\text { Vancomycin } \\
(\mu \mathrm{g} / \mathrm{ml})\end{array}$ & $\begin{array}{l}\text { 4,6-diamidino-2-phenylindole, dihydrochloride } \\
\text { (DAPI) Excitation Wavelength }(350 \mathrm{~nm}) \\
\text { Presence of Blue }=\text { DAPI release from cells, cell } \\
\text { membrane compromised }\end{array}$ & $\begin{array}{l}\text { Calcein AM Excitation Wavelength (494 nm). } \\
\text { Presence of green = Calcein AM retained by } \\
\text { cells, cells viable. }\end{array}$ \\
\hline 1000 & & \\
\hline 62.5 & &
\end{tabular}

Table 6: Fluorescence micrographs showing DAPI and calcein AM counterstains of HaCaT cells after 1 hour exposure to rifampicin.

\begin{tabular}{|l|l|l|l|}
\hline $\begin{array}{l}\text { Concentration of } \\
\text { Rifampicin } \\
(\mu \mathrm{g} / \mathrm{ml})\end{array}$ & $\begin{array}{l}\text { 4,6-diamidino-2-phenylindole, dihydrochloride } \\
\text { (DAPI) Excitation Wavelength }(350 \mathrm{~nm}) \\
\text { Presence of Blue = DAPI release from cells, cell } \\
\text { membrane compromised }\end{array}$ & $\begin{array}{l}\text { Calcein AM Excitation Wavelength (494 } \mathrm{nm}) . \\
\text { Presence of green = Calcein AM retained by } \\
\text { cells, cells viable. }\end{array}$ \\
\hline 1000 & & & \\
\hline & & & \\
\hline
\end{tabular}

(blue fluorescent stain) and lack of calcein (green fluorescent stain) proved cytotoxicity occurred in $\mathrm{HaCaT}$ cells within 1 hour exposure to the maximum concentration employed. Further analysis of the DAPI stain present at $1000 \mu \mathrm{g} / \mathrm{ml} \mathrm{rifampicin} \mathrm{in}$ Table 6 shows DNA to be relatively undefined compared with the positive ( $90 \%$ ethanol) control (Table 1). The presence of bright clustered bodies typical of chromatin condensation shows rapid cellular apoptosis could potentially be the cytotoxic mechanism of action of rifampicin (Table 6) [24]. The cell image (555 nm) at this concentration also shows distinct cell-like structures with intact membranes, showing that disruption of the cell membrane structures has not taken place and cellular apoptosis to be the possible mechanism of cell death.

For cationic antimicrobial peptides, there is a correlation between a larger ratio of aromatic residues, especially 
tryptophan, to cationic residues and a high degree of haemolysis and cell cytotoxicity $[25,26]$. Therefore the higher lipophilic: charge ratio provided by $\mathrm{C}_{12}-\mathrm{OOWW}-\mathrm{NH}_{2}(50 \%$ of amino acid residues are tryptophan) shows greater membrane interactions and haemolytic activity of equine erythrocytes than that provided by Maximin-4 (51\% hydrophobicity but no tryptophan residues). The grouping of sequentially consecutive positive charges to the termini of naturally occurring antimicrobial peptides such as magainin has been shown to provide a locus to which these molecules can adsorb to zwitterionic membranes [27]. Other factors such as $\alpha$-helicity, overall hydrophobicity, amphipathicity, hydrophobic movement and angle subtended by charged residues have also been shown to modulate activity against both microbial (particularly Gram-positive bacteria) and mammalian cells, with higher values of each reducing selectivity [28]. Tailoring selection towards microbial rather than eukaryotic membranes is therefore not as simple as reducing the hydrophobic: charge ratio. The potential in vivo activity of antimicrobial peptides may be lost under physiological salt and serum conditions with ionic strength a factor in both mammalian and microbial toxicity [29]. The high hydrophobicity provided by two tryptophan molecules in the tetrapeptide motif, together with the gradual increase in hydrophobicity by terminal acylation, is likely to ensure that membrane interactions are due to the molecule being highly hydrophobic rather than specific interaction with the anionic bacterial membranes. This is demonstrated by the large degree of activity expressed against zwitterionic mammalian cells. Attempts have been made to balance both salt resistance and membrane selectivity by variation of peptide hydrophobicity, charge, amphipathicity and degree of $\alpha$-helicity [30], with some naturally occurring peptides such as the tachyplesins and the polyphemusins displaying salt-insensitive antimicrobial activities [31].

There is much debate as to the benefit of switching L-enantiomeric amino acid residues with their D-counterparts. Several studies presented in the literature show that the use of D-enantiomers of amino acid residues has no effect on improving haemolytic properties of antimicrobial peptides that share the same primary sequence [32]. In other studies the incorporation of D-amino acids into non-cell selective lytic peptides decreased their activity against eukaryotic cells. This was due to loss of the $\alpha$-helical structure, whilst preserving their antibacterial properties via a carpet-like detergent mechanism as opposed to the formation of transmembrane (toroidal) pores [33] The main advantage of using more expensive D-enantiomers is to bestow proteolytic stability to antimicrobial peptides, which is alternatively provided to the tetrapeptide motif, by the use of the unnatural amino acid ornithine [34]. Hydrophobicity has a stronger influence in terms of cell toxicity. When this exceeds a threshold level, selectivity between prokaryotic and eukaryotic cells is lost, demonstrated by an increase in cytotoxicity [35]. Despite cytotoxicity against mammalian cells being demonstrated, no (or low) activity was demonstrated at the respective MICs of the compounds tested [1,2]. This selectivity for different membranes may potentially be harnessed in alternative areas of medicine. For example, some cationic peptides, such as
LL-37 [36], have been demonstrated to possess potent activity against mammalian tumour cells that possess a higher negative membrane potential than non-cancer cells due to a higher density of anionic molecules such as O-glycosylated mucins (rich in negatively charged saccharides comprised of sialic acids and sulphates), sialilated gangliosides [37], phosphatidylserine $[38,39]$ and heparin sulphates [40]. The majority of clinical trials completed or taking place involve the use of antimicrobial peptides in topical therapy. Lipopeptides such as polymyxin B are already utilised in skin creams, and, therefore, the potential therapeutic use of the most antimicrobially potent compound $\mathrm{C}_{12}$-00WW$\mathrm{NH}_{2}$ is still therapeutically viable. More advanced forms of topical treatment would include the use of these cationic compounds as aerosol therapy for the treatment of lung infections such as Pseudomonas aeruginosa colonisation in cystic fibrosis patients. This is especially true as the use of the polycationic lipopeptide, colistin, and the polycationic trisaccharides, tobramycin and gentamicin, have been successfully established $[41,42]$. However, owing to its increased action against Gram-positive bacteria, the release of these compounds from a polymeric/metallic/ceramic biomaterial in the prevention of biofilm-related device infection, where staphylococcal infection is particularly widespread, may prove more successful [43]. Despite the results obtained from the cytotoxicity studies outlined further in vivo, work involving human and/or animal studies would be required to correlate the true antimicrobial and toxic potential of such peptides clinically.

\section{References}

1. Laverty G, McLaughlin M, Shaw C, Gorman SP, Gilmore BF (2010) Antimicrobial activity of short, synthetic cationic lipopeptides. Chem Biol Drug Des 75(6): 563-569.

2. Laverty G, Gorman SP, Gilmore BF (2012) Antimicrobial peptide incorporated poly(2-hydroxyethyl methacrylate) hydrogels for the prevention of Staphylococcus epidermidis-associated biomaterial infections. J Biomed Mater Res A 100(7): 1803-1814.

3. Williams DP (2006) Toxicophores: Investigations in drug safety. Toxicology 226(1): 1-11.

4. Pirmohamed M, Breckenridge AM, Kitteringham NR, Park BK (1998) Adverse drug reactions. BMJ 316: 1295.

5. Mandell LA, Ball P, Tillotson G (2001) Antimicrobial safety and tolerability: differences and dilemmas. Clin Infect Dis 32(Suppl 1): 72 79.

6. Chalekson CP, Neumeister MW, Jaynes J (2003) Treatment of infected wounds with the antimicrobial peptide D2A21. J Trauma 54(4): 770774.

7. Duc Q1, Breetveld M, Middelkoop E, Scheper RJ, Ulrich MM, et al. (2007) A cytotoxic analysis of antiseptic medication on skin substitutes and autograft. Br J Dermatol 157(1): 33-40.

8. Hachem R, Reitzel R, Borne A, Jiang Y, Tinkey P, et al. (2009) Novel antiseptic urinary catheters for prevention of urinary tract infections: correlation of in vivo and in vitro test results. Antimicrob Agents Chemother 53(12): 5145-5149.

9. Laverty G, Gorman SP, Gilmore BF (2011) The potential of antimicrobial peptides as biocides. Int J Mol Sci 12(10): 6566-6596.

10. Wyllie AH, Kerr JF, Currie AR (1980) Cell death: the significance of apoptosis. Int Rev Cytol 68: 251-306. 
11. Hengartner MO (2000) The biochemistry of apoptosis. Nature 407(6805): 770-776.

12. Silva MT, do Vale A, dos Santos NM (2008) Secondary necrosis in multicellular animals: an outcome of apoptosis with pathogenic implications. Apoptosis 13(4): 463-482.

13. Lumley CE, Walker SR (1987) Predicting the safety of medicines from animal toxicity tests I. Rodents alone. Archives of Toxicology Supplement 11: 295-299.

14. Lumley CE, Walker SR (1987) Predicting the safety of medicines from animal toxicity tests II. Rodents and non-rodents. Archives of Toxicology Supplement 11: 300-304.

15. Rouveix B (2003) Antibiotic safety assessment. Int J Antimicrob Agents 21(3): 215-221.

16. Tillotson GS, Rybak J (2001) New milestones achieved in fluoroquinolone safety. Pharmacotherapy 21(3): 358-360.

17. Riss TL, Moravec RA (2004) Use of multiple assay endpoints to investigate the effects of incubation time, dose of toxin, and plating density in cell-based cytotoxicity assays. Assay Drug Dev Technol 2(1): 51-62.

18. Bhatia SK, Yetter AB (2008) Correlation of visual in vitro cytotoxicity ratings of biomaterials with quantitative in vitro cell viability measurements. Cell Biol Toxicol 24(4): 315-319.

19. Morikawa K, Yanagida M (1981) Visualization of individual DNA molecules in solution by light microscopy: DAPI staining method. J Biochem 89(2): 693-696.

20. Boutonnat J, Barbier M, Muirhead K, Mousseau M, Ronot X, et al (1999) Optimized fluorescent probe combinations for evaluation of proliferation and necrosis in anthracycline-treated leukaemic cell lines. Cell Prolif 32(4): 203-213.

21. Baskin DS, Ngo H, Didenko VV (2003) Thimerosal induces DNA breaks, caspase-3 activation, membrane damage, and cell death in cultured human neurons and fibroblasts. Toxicol Sci 74(2): 361-368.

22. Neri S, Mariani E, Meneghetti A, Cattini L, Facchini A (2001) Calceinacetyoxymethyl cytotoxicity assay: standardization of a method allowing additional analyses on recovered effector cells and supernatants. Clin Diagn Lab Immunol 8(6): 1131-1135.

23. Palma PF, Baggio GL, Spada C, Silva RD, Ferreira SI, et al. (2008) Evaluation of annexin $\mathrm{V}$ and Calcein-AM as markers of mononuclear cell apoptosis during human immunodeficiency virus infection. Braz J Infect Dis 12(2): 108-114.

24. Cheung NS, Pascoe CJ, Giardina SF, John CA, Beart PM (1998) Micromolar L-glutamate induces extensive apoptosis in an apoptoticnecrotic continuum of insult-dependent, e xcitotoxic injury in cultured cortical neurones. Neuropharmacology 37(10-11): 1419-1429.

25. Strom MB, Rekdal O, Svendsen JS (2002) Antimicrobial activity of short arginine- and tryptophan-rich peptides. J Pept Sci 8(8): 431-437.

26. Strom MB, Rekdal O, Svendsen JS (2002) The effects of charge and lipophilicity on the antibacterial activity of undecapeptides derived from bovine lactoferricin. J Pept Sci 8(1): 36-43.

27. Glukhov E, Stark M, Burrows LL, Deber CM (2005) Basis for selectivity of cationic antimicrobial peptides for bacterial versus mammalian membranes. J Biol Chem 280(40): 33960-33967.

28. Chen Y, Mant CT, Farmer SW, Hancock RE, Vasil ML, et al. (2005)
Rational design of alpha-helical antimicrobial peptides with enhanced activities and specificity/therapeutic index. J Biol Chem 280(13): 12316-12329.

29. Marr AK, Gooderham WJ, Hancock RE (2006) Antibacterial peptides for therapeutic use: obstacles and realistic outlook. Curr Opin Pharmacol 6(5): 468-472.

30. Friedrich C, Scott MG, Karunaratne N, Yan H, Hancock RE (1999) Saltresistant alpha-helical cationic antimicrobial peptides. Antimicrob Agents Chemother 43(7): 1542-1548.

31. Tam JP, Lu YA, Yang JL (2002) Correlations of cationic charges with salt sensitivity and microbial specificity of cystine-stabilized $\beta$-strand antimicrobial peptides. J Biol Chem 277(52) : 50450-50456.

32. Chen Y, Vasil AI, Rehaume L, Mant CT, Burns JL, et al. (2006) Comparison of biophysical and biologic properties of alpha-helical enantiomeric antimicrobial peptides. Chem Biol Drug Des 67(2): 162173.

33. Papo N, Oren Z, Pag U, Sahl HG, Shai Y (2002) The consequence of sequence alteration of an amphipathic alpha-helical antimicrobial peptide and its diastereomers. J Biol Chem 277(37): 33913-33921.

34. Bisht GS, Rawat DS, Kumar A, Kumar R, Pasha S (2007) Antimicrobial activity of rationally designed amino terminal modified peptides. Bioorg Med Chem Lett 17(15): 4343-4346.

35. Dathe M, Wieprecht $T$ (1999) Structural features of helical antimicrobial peptides: their potential to modulate activity on model membranes and biological cells. Biochim Biophys Acta 1462(1-2): 7187.

36. Schweizer F (2009) Cationic amphiphilic peptides with cancerselective toxicity. Eur J Pharmacol 625(1-3): 190-194.

37. Lee HS, Park CB, Kim JM, Jang SA, Park IY, et al. (2008) Mechanism of anticancer activity of buforin IIb, a histone H2A-derived peptide. Cancer Lett 271(1): 47-55.

38. Utsugi T, Schroit AJ, Connor J, Bucana CD, Fidler IJ (1991) Elevated expression of phosphatidylserine in the outer membrane leaflet of human tumor cells and recognition by activated human blood monocytes. Cancer Res 51(11): 3062-3066.

39. Dobrzynska I, Szachowicz-Petelska B, Sulkowski S, Figaszewski Z (2005) Changes in electric charge and phospholipids composition in human colorectal cancer cells. Mol Cell Biochem 276(1-2): 113-119.

40. Kleeff J, Ishiwata T, Kumbasar A, Friess H, Buchler MW, et al. (1998) The cell-surface heparan sulfate proteoglycan glypican-1 regulates growth factor action in pancreatic carcinoma cells and is overexpressed in human pancreatic cancer. J Clin Invest 102(9): 1662-1673.

41. Jensen T, Pedersen SS, Garne S, Heilmann C, Hoiby N, et al. (1987) Colistin inhalation therapy in cystic fibrosis patients with chronic Pseudomonas aeruginosa lung infection. J Antimicrob Chemother 19(6): 831-838.

42. Kun P, Landau LI, Phelan PD (1984) Nebulized gentamicin in children and adolescents with cystic fibrosis. Aust Paediatr J 20(1): 43-45.

43. Shukla A, Fleming KE, Chuang HF, Chau TM, Loose CR, et al. (2010) Controlling the release of peptide antimicrobial agents from surfaces. Biomaterials 31(8): 2348-2357. 